Article

\title{
Indoor Climate Modelling and Economic Analysis Regarding the Energetic Rehabilitation of a Church
}

\author{
Florin-Emilian T,urcanu *, Cătălin-George Popovici, Marina Verdeș, Vasilică Ciocan \\ and Sebastian-Valeriu Hudișteanu
}

Department of Building Services, Faculty of Civil Engineering and Building Services, Gheorghe Asachi Technical University of Iasi, 700050 Jassy, Romania; catalin.popovici@tuiasi.ro (C.-G.P.); marina.verdes@tuiasi.ro (M.V.); vasilica.ciocan@tuiasi.ro (V.C.); sebastian.hudisteanu@tuiasi.ro (S.-V.H.)

* Correspondence: emilian-florin.turcanu@tuiasi.ro; Tel.: +40-0748-034-588

Received: 11 April 2020; Accepted: 1 June 2020; Published: 2 June 2020

\begin{abstract}
Background: The aim of our study was to identify an optimal heating system for the analyzed church. We also evaluated the energy consumption of the existing system and of those proposed in order to choose the best heating system. Methods: We analyzed the current existing heating system, a mixed system (static heaters and hot air heating) in a Romanian heritage church, build in the 16th century, and we compared it with an underfloor heating system that has been mentioned in the literature as an alternative for church heating. We used a computational fluid dynamics (CFD) analysis of the indoor climate with two turbulence models (k- $\varepsilon$ and $k-\omega)$. Results: Comparing the two heating systems through boxplot graphs, we could highlight pertinent conclusions regarding the temperatures and velocities of the measured air currents. Thus, of all the heating systems, the underfloor heating had the lowest temperatures, but the highest air velocities, in the churchgoers area, especially under the towers zone. Conclusions: We observed that the underfloor heating system was more efficient than the existing heating system (static heaters and hot air heating), ensuring heritage conservation and high thermal comfort to the churchgoers.
\end{abstract}

Keywords: indoor climate; energetic rehabilitation; church heating; CFD modelling

\section{Introduction}

Buildings are key elements for European Union (EU) actions on energy efficiency. In Romania, $45 \%$ of the total energy consumption of a building is used for heating it. This is the reason why improvements to the energy efficiencies of buildings are required [1].

Buildings that function as a place of worship, whether or not they are located within monastic settlements that also have heritage value, are usually painted churches, and their fresco gives value to the heritage [2,3]. The preservation of interior paintings should be a major concern at the state level, as both national and world heritage are involved. This is the minimum requirement that is associated with heritage buildings in the spirit of European Directive 31/2020/EU [4].

Churches are part of the heritage of Romania, and this must be preserved and cherished. Their construction meant the fulfilment of a Christian ritual that created sacred buildings in which man would bring glory and honor to divinity. Throughout time, man has integrated various techniques and technologies into these constructions to increase their comfort. These have resulted in new methods of construction, better and more durable materials, impressive paintings and frescoes, uplifting, and increased thermal comfort during religious services through the adoption of heating systems [5,6].

The quality of heritage buildings automatically implies the inclusion of places of worship/monastic settlements in the tourist circuit. The main difference concerning the initial function of the buildings is 
the presence of tourists and the development of activities related to tourism in the space of the monastic settlement. The attraction represented by heritage-painted churches included in intensely publicized tourist routes leads to significant increases in the number of people temporarily attending the religious service. These people come from the internal microclimate and represent a major disturbance with the reference situation. On the other hand, the modernization of buildings to achieve conditions of thermal comfort in the cold season amplifies the presence of tourists and the disturbance of the indoor climate $[7,8]$. This can reveal appearance of condensation in the areas with high thermal bridges, at the intersections of the walls, at the base, and at the roof (Figure 1) [5,6].

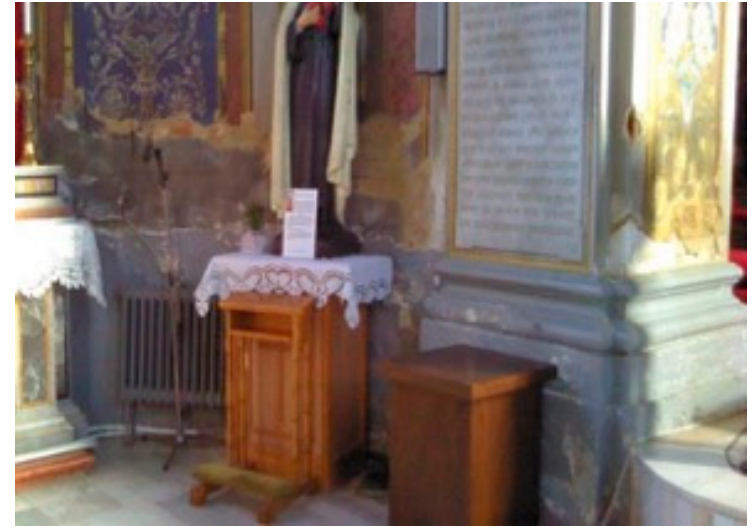

(a)

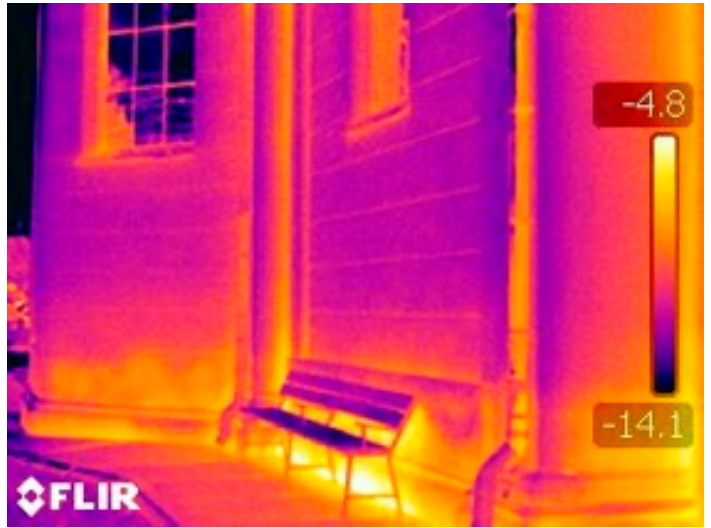

(b)

Figure 1. (a) Degradation due to the appearance of condensation at the base. (b) Degradation captured in images with thermal vision cameras show the areas with thermal bridges that favor the appearance of condensation.

Historical monument buildings that have a large number of operating hours per year, and so they must be energy efficient. Museums, schools, offices, hospitals, hotels, etc., belong to this category. They exist in almost all localities and have an important shares in energy consumption. Some of them also involve the provision of special indoor humidity conditions in order not to affect the exhibited heritage objects. In Jassy, for example, there are numerous such buildings, like the St. Three Hierarchs Monastery Assembly, the Metropolitan Cathedral, the Palace of Culture, the University of Al. I. Cuza, a military hospital (former high school), a railway station, a city hall, the National Theatre. Churches are a special category due to the intermittent nature of their use and the fact that, in churches, the faithful keep their street clothes, so the demands for thermal comfort are more modest $[5,6]$.

Even if the current normatives do not require the existence of an energy efficiency certificate for historical monuments, the architects recommend it in order to see the thermal insulation and the energy consumption of the building [7].

The actions of the rehabilitation and thermal modernization of buildings aims to reduce energy consumption for heating, the preparation of hot water for consumption, and lighting. In 2013, Beck Water and his coworker reported some results from studies on non-warming cult buildings in Austria exposed to an alpine climate. They found that cult buildings with a high thermal mass did not show rapid variations of the interior microclimate; the temperatures on the inside of the exterior walls were between 2 and $5{ }^{\circ} \mathrm{C}$ in winter and between 13 and $15^{\circ} \mathrm{C}$ in the warm period; indoor air temperatures during winter had an average value of $0{ }^{\circ} \mathrm{C}$ and had an average value of around $20^{\circ} \mathrm{C}$ during summer; the relative humidity of the indoor microclimate was between $60 \%$ and $65 \%$, except for some days with lower temperatures [8]. A study of this type establishes the starting point for assessing the indoor climate and the strategy of heating or heritage conservation where appropriate, considering that the temperate continental climate is specific to Austria and Romania. It is also very important to establish the parameters that may influence the indoor climate, for each type of system heating. For example, Camuffo et al. observed that setting the floor temperature is often a compromise between 
three factors: the outdoor climate, the comfort of the churchgoers, and the conservation of heritage [6]. Additionally, in some studies, it was observed that condensation and mold formation occur in over $30 \%$ of churches due to the fact that they are not provided with adequate thermal insulation, and these phenomena are much more pronounced around thermal bridges $[9,10]$.

Increasing energy efficiency has beneficial effects on the environment. Solutions that are adopted for the modernization of heating, hot water, and lighting systems-correlated with those of thermal rehabilitation - must meet the aesthetic criteria that sometimes affect the historical value of buildings [11].

Thus, the existing literature on this topic has only evaluated indoor climates for existing heating systems or indoor comfort in churchgoers' areas without a complete and comparative evaluation of existing and proposed heating systems $[12,13]$.

The aim of our study was to evaluate the energy consumption of an existing system and of a proposed one in a Romanian church in order to identify the optimal heating system for it.

\section{Materials and Methods}

In order to achieve our goal, we analyzed the current existing heating system of the chosen church, a mixed system (static heaters and hot air heating). Furthermore, we compared this system with an underfloor heating system, considering that it is also a good alternative for heating in the church. We studied an orthodox church built to the dedication of the Three Holy Hierarchs, located in the city of Jassy, in the third wind zone and the third climatic zone of Romania, with an outdoor temperature during winter of $-18{ }^{\circ} \mathrm{C}$ (the design temperature). The building was constructed in the 16th century. Due to earthquakes and fires, the church has been restored several times. The church has the plan view of a Greek cross, with the following parts: a narthex (at the entrance), a middle section for the nave, and the altar in the front. (Figure 2). The architecture of the church is that of the Moldavian churches, with the influence of Transylvanian gothic style (Figure 3).

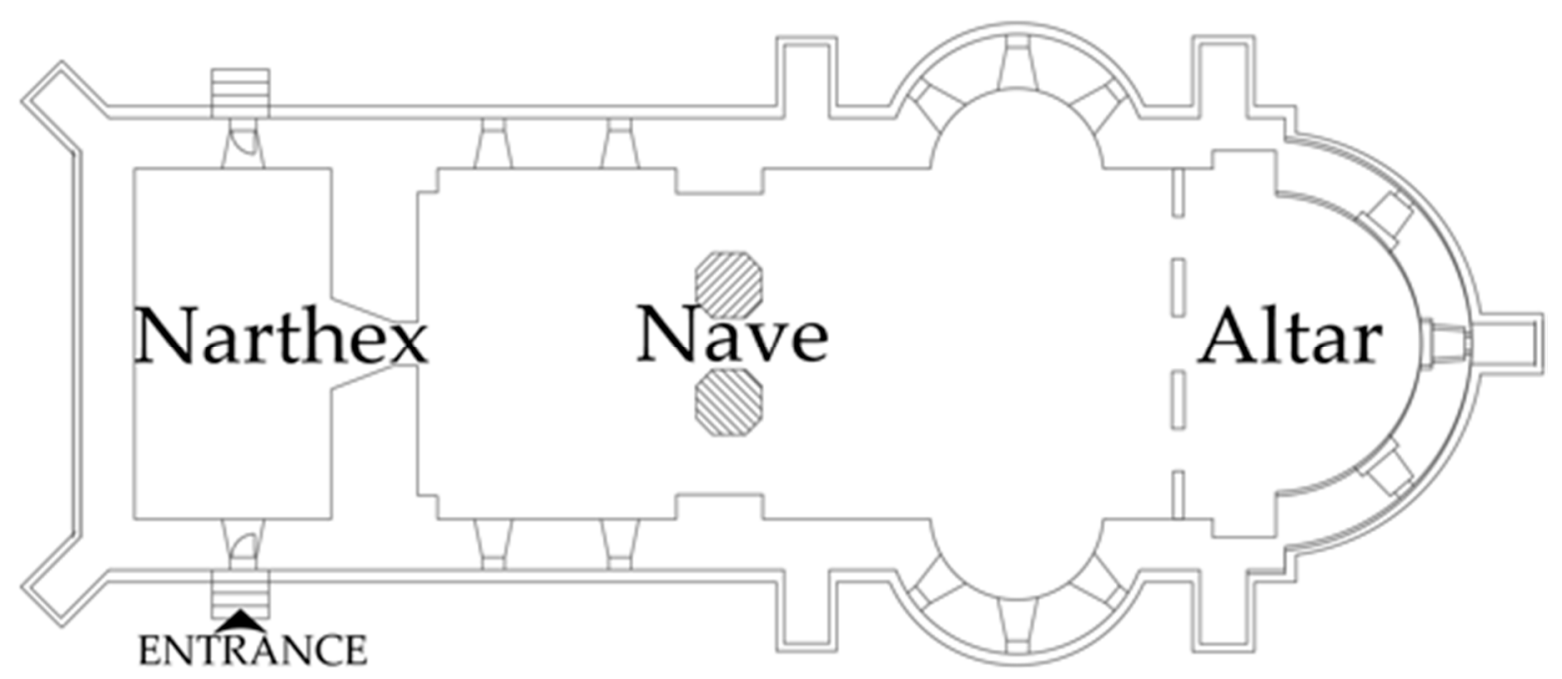

Figure 2. The current form in the church plan of Three Holy Hierarchs in Jassy. 


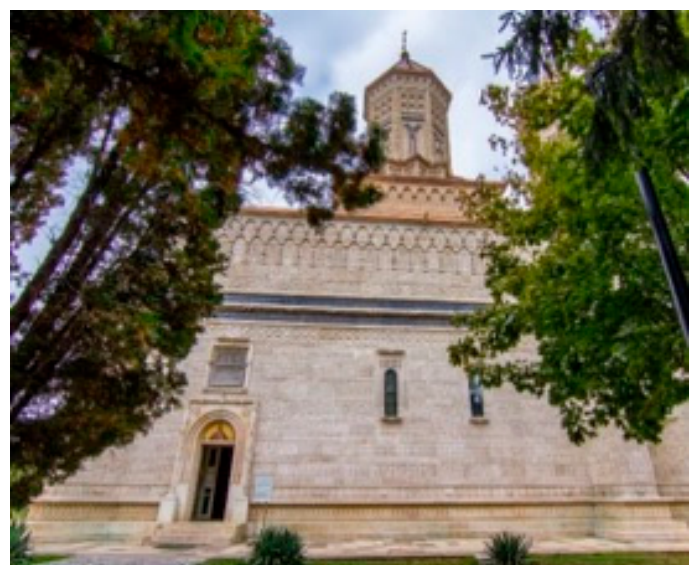

(a)

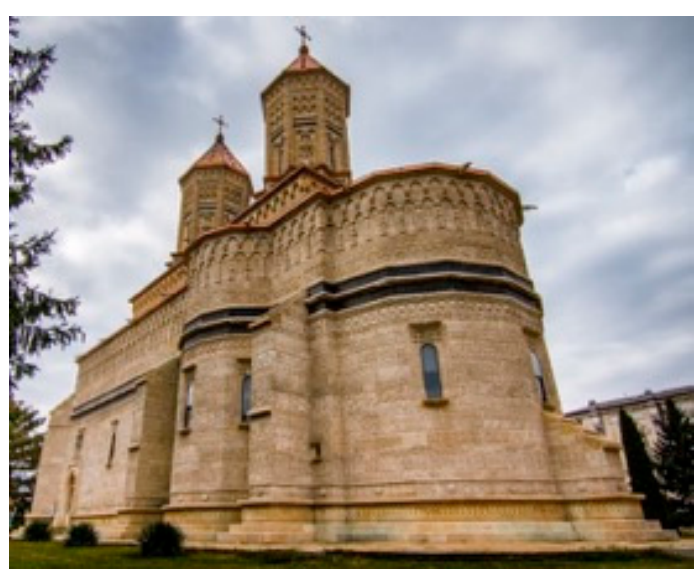

(b)

Figure 3. View of the Three Holy Hierarchs church in Jassy: (a) main entrance and (b) side view.

The interior microclimate from the church, as well as of the physical parameters, could not be determined without investigative tools. For the microclimate in the church, we used sensors from Testo that were mounted in the church during the winter for 2 months. The sensors were placed in the area of the second tower of the church, in a vertical plane. (Figure 4).

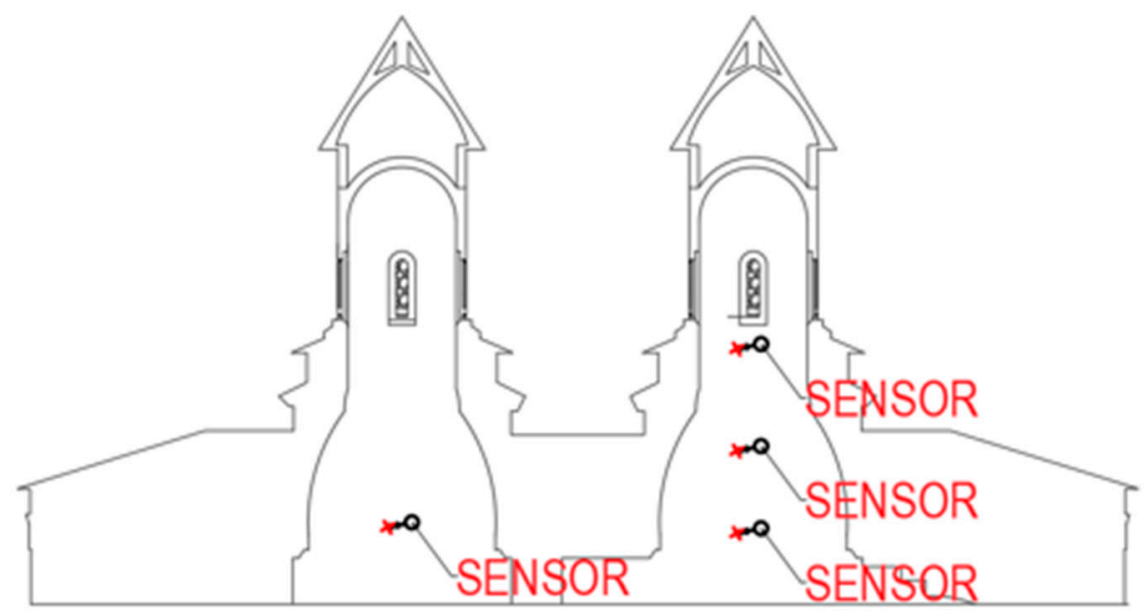

Figure 4. Sensors placed in the church.

Thermal imaging is widespread in the field of construction, in particular in the fields of heat loss assessment and thermal bridge identification. We used the thermal imaging to determine the insulation defects, air infiltration, heat loss through the closing elements of the building, and the discovery of areas with potential to develop dampness and mold. We decided to study other defects of construction materials and to monitor the heating systems in order to detect temperature variations.

With the measuring and recording equipment, the main parameters were captured: temperature, humidity, and air velocities. Sensors were placed at a height of $1.8 \mathrm{~m}$, in areas that were not affected by drafts or cold radiation of the outer tire elements (exterior walls, windows and exterior doors). Also, the sensors were not under the direct influence of heating equipment.

We studied the existing heating system in the church in the year 2017-a mixed heating system (static heaters with hot air system). The indoor and outdoor temperature were measured in the winter. Knowing the envelope parameters and the thermal resistance of the walls and windows, we made the geometrical model for computational fluid dynamics (CFD) of indoor climate (Table 1). The CFD model analysis was used to see the other effects of the heating system, like the deterioration of the paints and walls, that could not be seen with the naked eye. 
Table 1. The boundary conditions imposed for the computation fluid dynamics (CFD) analysis in the Three Hierarchs church.

\begin{tabular}{|c|c|c|c|}
\hline No. & Envelope Element & \multicolumn{2}{|c|}{ Type of the Heating System } \\
\hline \multirow[t]{2}{*}{1} & 2 & 3 & 4 \\
\hline & & Static heaters with hot air system & Underfloor Heating System \\
\hline \multirow{5}{*}{ Temperature $\left({ }^{\circ} \mathrm{C}\right)$} & Exterior Walls & -16 & -16 \\
\hline & Ceiling & -15 & -15 \\
\hline & Input grids for hot air & 35 & - \\
\hline & Ground plate & 10 & 10 \\
\hline & Windows and Doors & -16 & -16 \\
\hline Pressure (Pa) & & Relative pressure & \\
\hline \multirow{5}{*}{$\begin{array}{l}\text { Heat transfer coefficient } \\
\qquad U\left(W / m^{2} K\right)\end{array}$} & Exterior walls & 0.652 & 0.652 \\
\hline & Windows and doors & 2.379 & 2.379 \\
\hline & Ceiling & 1.518 & 1.518 \\
\hline & Ground plate & 0.818 & 0.818 \\
\hline & Tower walls & 1.276 & 1.276 \\
\hline \multirow{2}{*}{ Air velocity $(\mathrm{m} / \mathrm{s})$} & Inlet grids for hot air & 0.25 & - \\
\hline & Extraction grids & 0.15 & - \\
\hline \multirow{2}{*}{ Heat flux $\left(W / m^{2}\right)$} & Static heater & 200 & - \\
\hline & Underfloor heating & - & 100 \\
\hline \multicolumn{4}{|c|}{ Heat flow generated by people is imposed at $80(\mathrm{~W})$} \\
\hline
\end{tabular}

The limit conditions imposed for the inlet air temperature and air velocity were taken from the operating regime of the heating installation, and the heat flux imposed on the radiators was determined from a guide for determining the thermally equivalent surface of a heating body.

The resultant heat was calculated with the relation:

$$
Q=\dot{m} \times C_{p} \times \Delta T
$$

where:

$\dot{m}$-fluid flow rate;

$C_{p}$-specific heat of the fluid;

$\Delta T$ - the temperature difference between supply pipes lines and return pipes lines from boilers.

Based on literature studies, the turbulence models selected for CFD analysis of the church were $k-\varepsilon$ and $k-\omega$ [14-16]. We made an initial discretization of 2 million elements with an unstructured meshing type. Subsequently, we increased the number of meshing elements to a maximum of 8 million elements for the existing heating system and 10 million elements for the proposed heating system. This limit was selected by considering the fact that we did not have any variations in the studied parameters at this meshing. After establishing the geometric model, the competition of the boundary condition, and the selection of the underfloor heating system based on the literature studies of the Friendly-Heating Project [5] and Climate for Culture [6], we made the following simulations (Figure 5). 


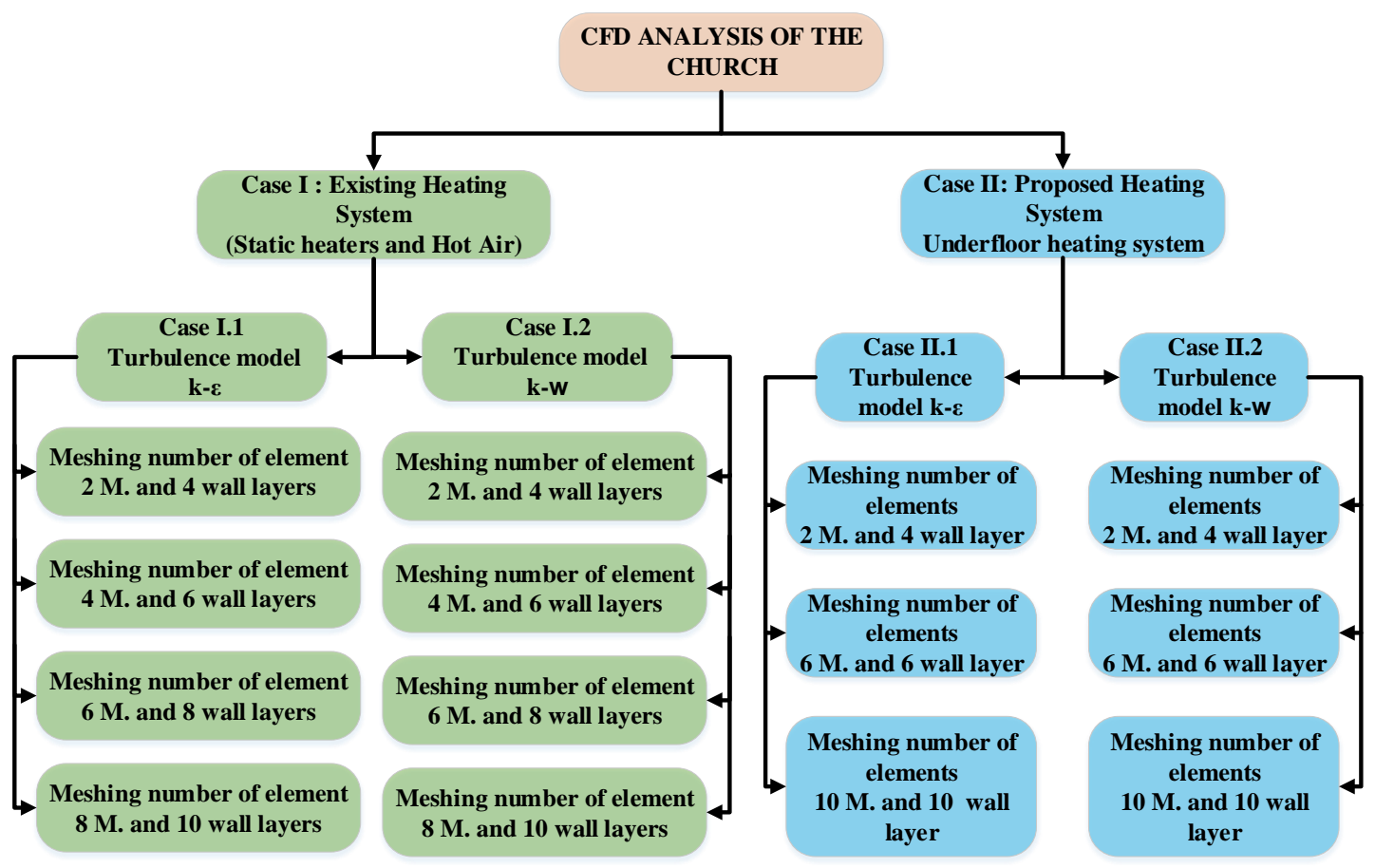

Figure 5. CFD analysis scheme of the church. We evaluated the existing heating system and the proposed one; for each of these, we used two different turbulence models (k- $\varepsilon$ and $k-\omega)$. We used different levels of meshing and wall layers that were gradually increased until we did not have any variations in the studied parameters.

\section{Results}

\subsection{Thermovision Images}

The chosen monument has historical value and is the part of the Romanian cultural heritage because it is representative of this area of the country through its architectural style. Its strong structure is made of solid brick masonry. The edifice being over 350 years old, the materials used in its construction, and the weather conditions it has experienced have led to multiple degradations in the structure of the building. When heat losses are high, several problems arise, such as condensation favored in areas that fall below the dew point temperature in front of the interior elements. This phenomenon primarily affects the finishing details and creates an unsightly appearance, but it also leads to degradations such as the detachment of the support layers for paintings and plasters. In Figure 6a, the influence of the convective air current caused by the static heating system that rises and washes the paints from the walls can be observed; this leads, in time, to drying and detachment from the support walls. In Figure $6 \mathrm{~b}$ we presented the differences in the wall thickness, in the area of crypts created in the side walls that lead to massive heat losses. Due to this and the contribution of the interior humidity, degradations have appeared in this area in the form of condensation and mold that have destroyed the paintings.

The roof is of a non-insulated roof type with sheet covers. The joinery is metallic with simple windows. The floor above the useful space is made of brick, and there is a layer of reinforced concrete over. The floor is of the cold type made of marble. The thickness of the walls varies from $180 \mathrm{to} 80 \mathrm{~cm}$. With widths of 40.61 and $15.04 \mathrm{~m}$ and an average height of $9.81 \mathrm{~m}$, the church has a volume of $2710 \mathrm{~m}^{3}$ with an entire surface of $351.47 \mathrm{~m}^{2}$. The building service systems that serve the building are those of electricity and thermal energy [3,4]. The lighting is done with incandescent bulbs, and the heating is done with radiators and hot air inlet grids placed in the base floor (Figure 7). 


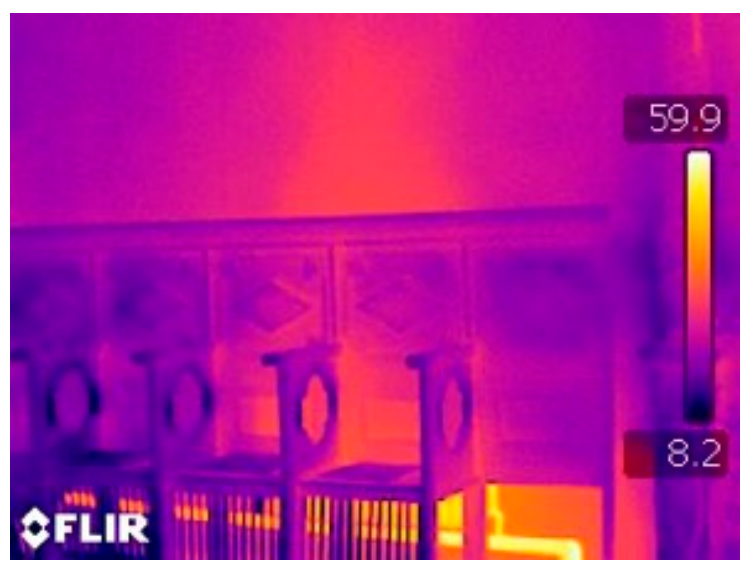

(a)

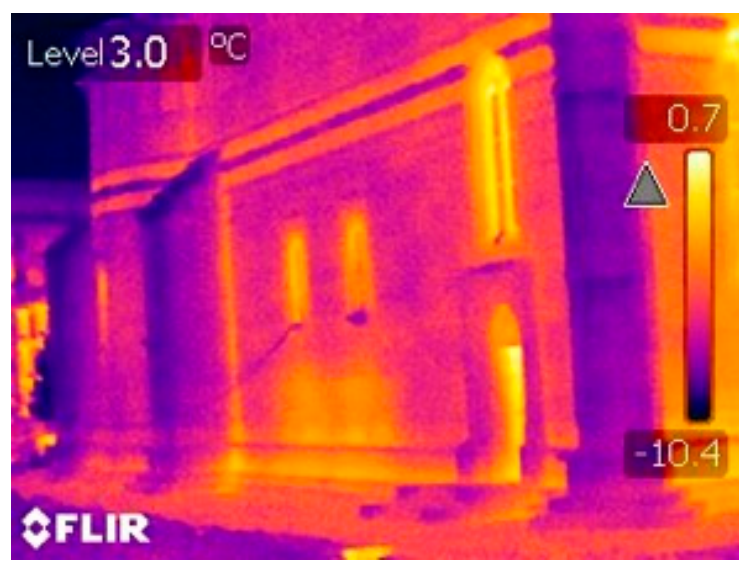

(b)

Figure 6. Thermal vision images that capture (a) the effects of the static heater over the walls and (b) thermal bridges in the outer walls.
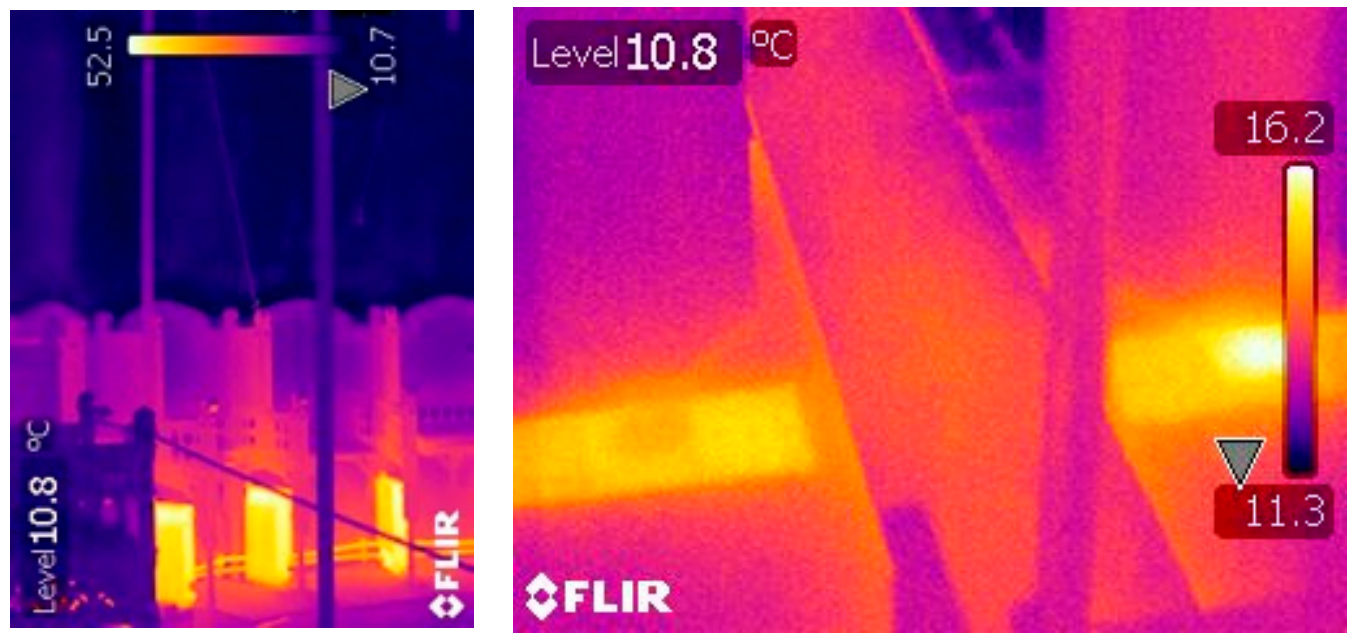

Figure 7. Thermal imaging camera images of the heating system in the church.

\subsection{Heating with Radiators Modelled with Ansys Fluent}

The fundamental objective of numerical modelling using the CFD analysis of the existing heating system was a better understanding of the influence of the heating system on the indoor climate of the church regarding not only the delimiting elements of the church envelope but also the thermal comfort of churchgoers. The resulting information was evaluated in order to provide solutions in response to a series of degradations observed in the church—both with the naked eye and with the help of the thermal imaging cameras. These solutions aimed to improve the indoor climate in order to preserve the heritage of the church, as well as the comfort of the churchgoers.

The CFD modelling was done with a section plan that was taken on the church in the longitudinal, transversal section of the church and in the plane of the human occupants at the height of $1.8 \mathrm{~m}$.

The software used for CFD analysis was ANSYS FLUENT, and we performed a 3D numerical study of the indoor climate. A fine meshing was generated with a minimum step of $5 \mathrm{~cm}$ and a maximum of $8 \mathrm{~cm}$. A Cartesian coordinate system was used to construct the model. In the CFD model, the flow, continuity, and energy equations were solved. The mode of the implementation of these equations was standard, simple, derived from the first order for the momentum, kinetic energy, flow, and energy equations. The standard $k-\varepsilon$ model with standard wall functions was used because the heat was not introduced by forced ventilation but by the natural circulation generated by the radiators, while Boussinesq's approximation was used for air density. 
Figure 8 shows the result of the analysis performed for the existing heating system for cases I.1 and I.2. It is easy to observe the profiles of the air velocities with different temperatures, their arrangement and the way the church geometry influences them. Also, in this figure are presented the temperatures that exist inside the church. The warm air rises to the ceiling, forming a layer at the top. Colder, denser air accumulates on the floor. After air circulation with different temperatures, they tend to stabilize, forming a strong stratification of the air.

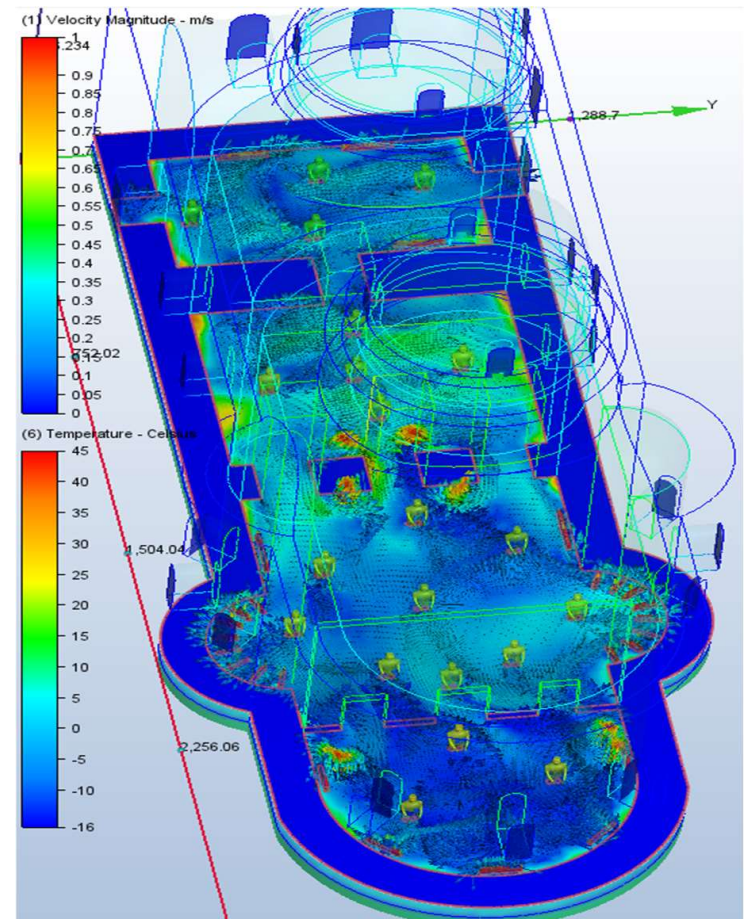

(a)

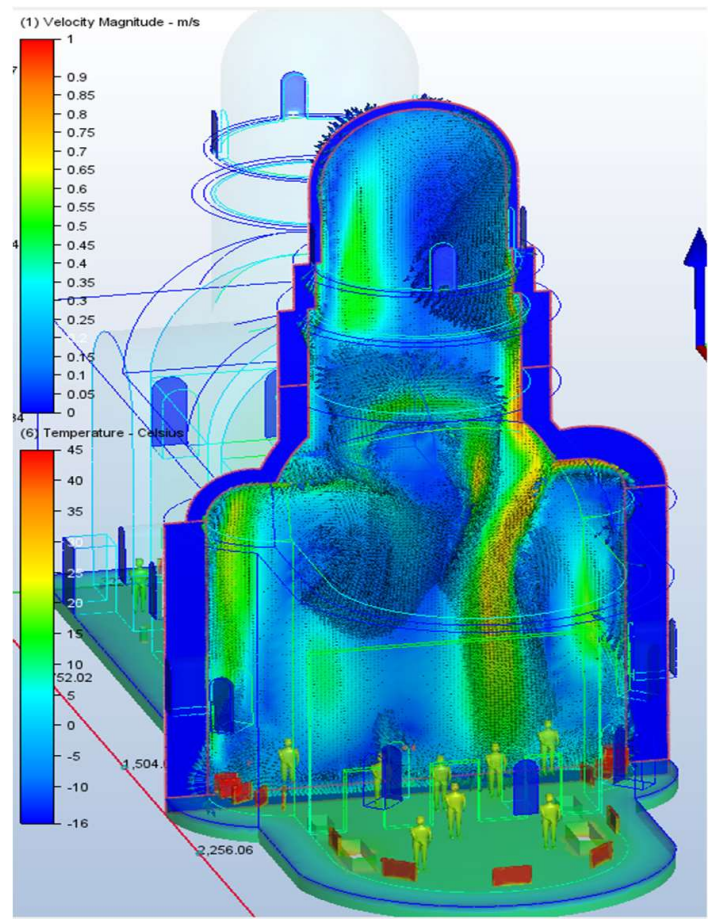

(b)

Figure 8. Profiles of temperature and air velocity contour in the church after CFD modelling: (a) horizontal velocity field in the occupied area and (b) vertical velocity field of air currents in the area of the nave.

The air around the radiators has low density and rises on the walls behind them, thus, having a destructive effect on the paintings. In Figure 8, this effect is seen in the following manner: the air currents entrain the dust particles with negative effects on the paintings and frescoes.

In order to detail the data from the two turbulence models (standard $k-\varepsilon$ and $k-\omega$ ) and the values of the in situ measurements, we performed a statistical boxplot analysis. We chose this method of representation for the mathematical because it is a convenient method of processing and displaying groups of data from measurements. By analyzing the air currents and the temperatures in the longitudinal plane, we could observe the variation of the air currents on the graph; these currents had higher values in the nave and lower values in the other areas. Figure 9 shows the result of the analysis performed for the proposed heating system for cases II.1 and II.2.

By comparing the two heating systems through boxplot graphs, we can highlight pertinent conclusions regarding the temperatures and velocities of the measured air currents. As such, of all the heating systems, the underfloor heating had the lowest temperatures (Figure 10). Regarding the air currents, we observed that for the underfloor heating system, the velocities were significantly higher in the nave area (Figure 11).

By comparing the two different types of turbulence models, we could also observe that the k- $\varepsilon$ model had temperature and air velocity values that were closer to those measured with indoor air quality (IAQ) sensor. 


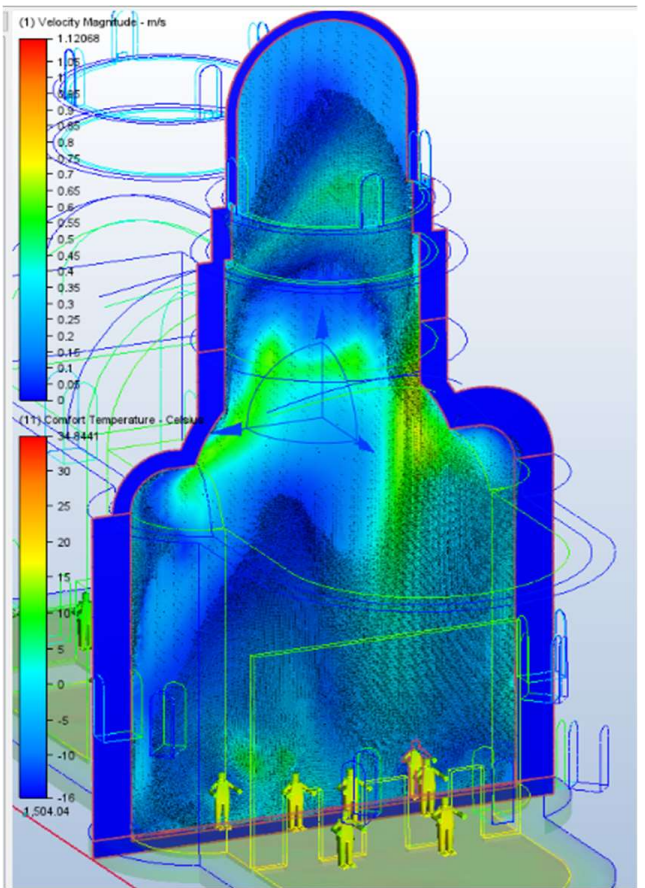

(a)

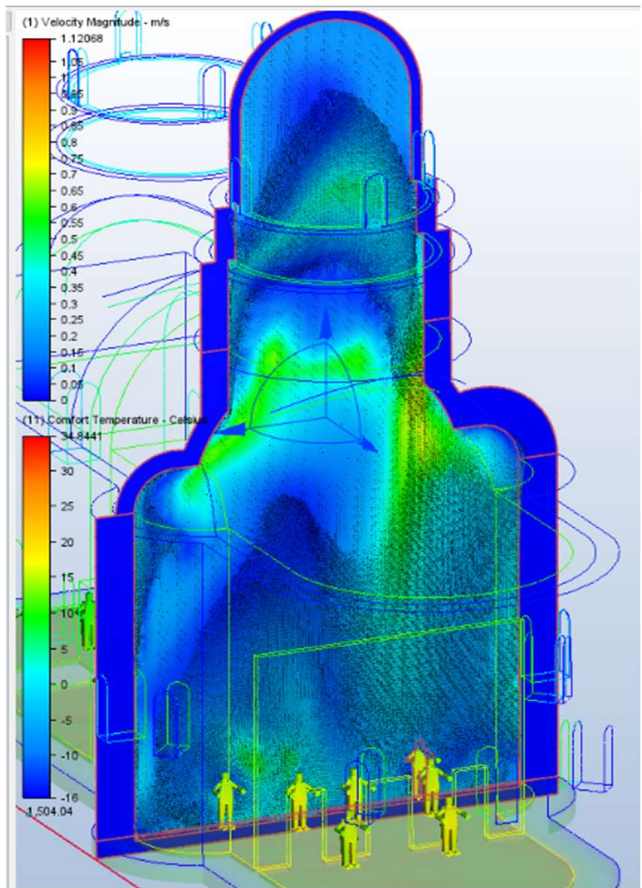

(b)

Figure 9. Profiles of temperature and air velocity contour in the church after CFD modelling: (a) vertical velocity field of air currents in the area of the nave and (b) horizontal velocity field in the longitudinal section.

\section{Comparison between temperature values from simulaton and in situ measures}

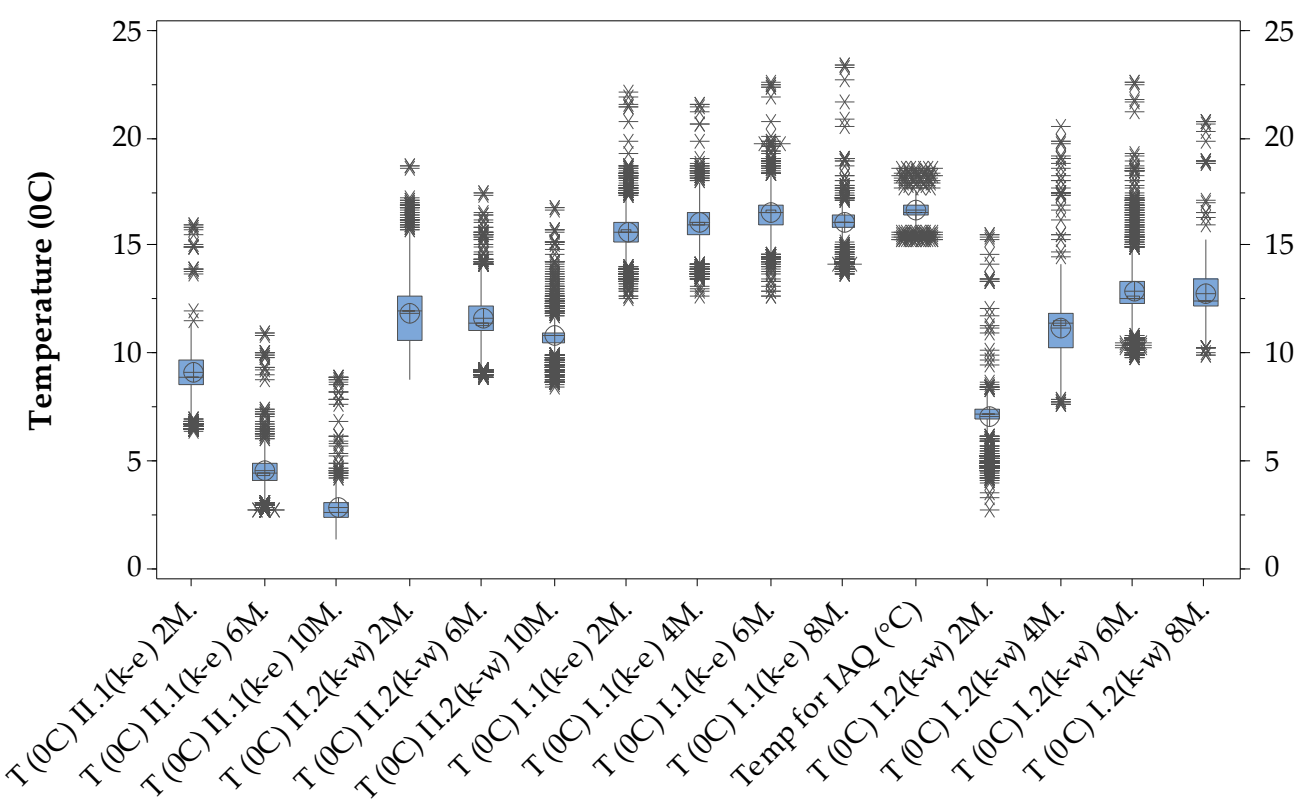

Figure 10. Comparison between temperature values for both turbulence models (standard k- $\varepsilon$ and $k-\omega)$ : the existing heating system, the proposed heating system, and the indoor air quality (IAQ) probe. 


\section{Comparison between air velocity values from simulaton and in situ measures}

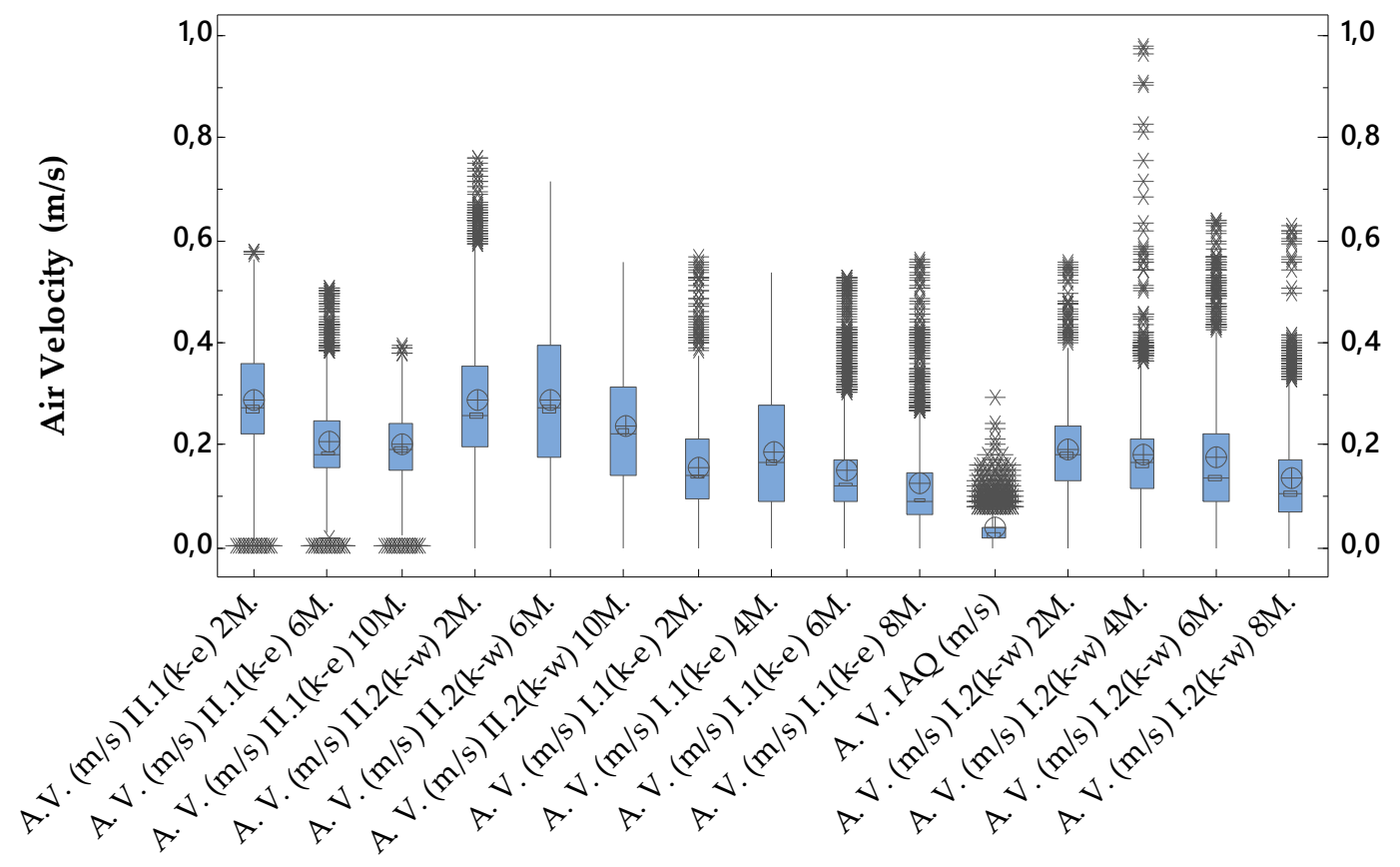

Figure 11. Comparison between air velocity values for both turbulence models (standard k- $\varepsilon$ and $k-\omega$ ): the existing heating system, the proposed heating system, and the indoor IAQ probe.

\subsection{Analysis of the Studied Building Energy Performance}

We also performed a thermo-technical calculation of the envelope elements according to the normative C107-2005. We determined the corrected thermal resistances of the closing elements $\mathrm{R}^{\prime}$ $\left(\mathrm{m}^{2} \mathrm{~K} / \mathrm{W}\right)$ compared to the standard thermal resistances $\mathrm{R}^{\prime} \min \left(\mathrm{m}^{2} \mathrm{~K} / \mathrm{W}\right)$. The criterion for satisfying the requirement of thermal insulation was $R^{\prime} \geq R_{\min }^{\prime}$. The comparative values are presented in Table 2 .

Table 2. The thermomechanical characteristics of the existing envelope.

\begin{tabular}{cccc}
\hline \multirow{2}{*}{ Elements } & $\mathbf{A}$ & $\mathbf{R}^{\prime}$ & $\mathbf{R}_{\text {min }}^{\prime}$ \\
\cline { 2 - 4 } & $\mathbf{m}^{\mathbf{2}}$ & $\mathbf{m}^{\mathbf{2}} \mathbf{K} / \mathbf{W}$ & $\mathbf{m}^{\mathbf{2}} \mathbf{K} / \mathbf{W}$ \\
\hline North wall & 147.16 & 0.652 & 1.800 \\
\hline West wall & 51.68 & 0.652 & 1.800 \\
\hline East wall & 61.41 & 0.652 & 1.800 \\
\hline South wall & 147.16 & 0.652 & 1.800 \\
\hline Roof & 305.91 & 1.518 & 5.000 \\
\hline Decking & 266.01 & 0.818 & 4.500 \\
\hline Windows & 35.36 & 0.330 & 0.770 \\
\hline
\end{tabular}

The analysis showed that most of the building envelope elements did not meet the minimum thermal insulation requirements. The annual consumptions were calculated according to the normative NP 048-2000. This norm takes the heat transfer in a non-stationary regime through a building envelope into account. The heat contributions due to the human activities and the solar radiation were also considered. The estimation of annual consumptions was used for the energy certificate [7].

In this way, the annual consumption was as follows:

Yearly consumption for heating: $\mathrm{Q}_{\text {Heat }}^{\text {year }}=257.35 \mathrm{kWh} / \mathrm{m}^{2}$ year,

Yearly consumption for hot water preparation: $\mathrm{q}_{\text {hotwater }}^{\text {year }}=30.15 \mathrm{kWh} / \mathrm{m}^{2}$ year, 
Yearly consumption for lighting preparation: $\mathrm{W}_{\text {lighting }}^{\mathrm{year}}=2876 \mathrm{kWh} / \mathrm{m}^{2}$ year, Total annual consumption: $\mathrm{Q}_{\text {Heat }}^{\text {year }}=316.26 \mathrm{kWh} / \mathrm{m}^{2}$ year.

\subsection{Completion of the Energy Certificate}

Churches have intrinsic value via their heritage, and they also have energy consumption, especially in a climatic zone where the duration of the heating season lasts for several months. In Romania, the duration of the heating season is, on average, 3600 degrees-days $(K \cdot h)$. This is the reason why we considered it necessary to carry out an energetic classification of the church that we analyzed. The energy certificate of the building was decided based on its consumptions, and it was attributed the energy classification " $\mathrm{D}$ " and a value of $\mathrm{Q}$ (Heating/Year) $=3162 \mathrm{kWh} / \mathrm{m}^{2}$ for the annual consumption of heat for heating, hot water, and lighting (Figure 12).

THERMAL ENERGY PERFORMANCE OF THE BUILDING

- Building Energy Classification for each domain

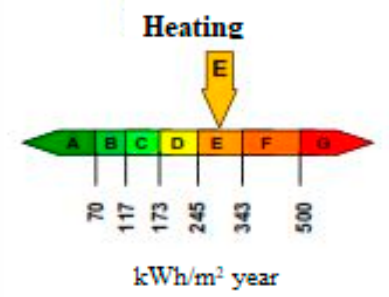

Total Energy Consuption

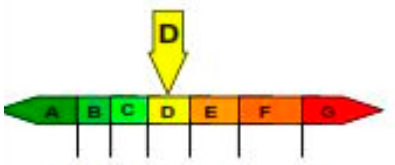

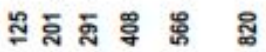

$\mathrm{kWh} / \mathrm{m}^{2}$ year

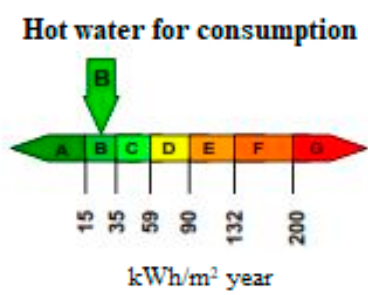

Energy for HVAC system

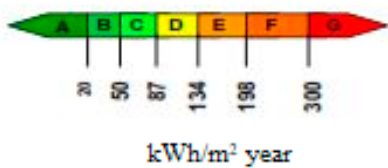

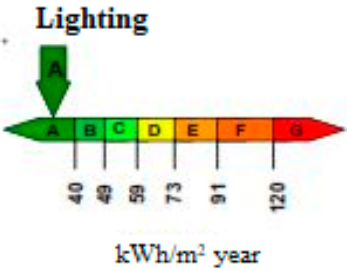

Energy for Ventilaton

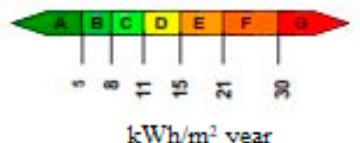

$\mathrm{kWh} / \mathrm{m}^{2}$ year

Figure 12. Grids regarding the energy classification of the audited building $\mathrm{kWh} / \mathrm{m}^{2}$ year.

\subsection{Proposals on Energy Modernization Solutions}

Based on its historical character, the façade of this church cannot have an increase in thermal resistance to reduce heat transfer. The only place where the thermal resistance can increase is at the levels of the floor and the roof.

Two economic and technical rehabilitation models were analyzed:

The first was solution that only involved the thermal rehabilitation of the building, specifically interventions to the construction site to improve the thermal protection of the floor under the bridge. It was proposed to install a thermal insulation layer made of mineral wool with a thickness of $15 \mathrm{~cm}$. The new, corrected thermal resistance created was $\mathrm{R}^{\prime}=3367\left(\mathrm{~m}^{2} \mathrm{~K} / \mathrm{W}\right)$. To improve the thermal protection of the ground floor, it was proposed to install a layer of thermal insulation of extruded polystyrene plates with a thickness of $10 \mathrm{~cm}$. The new, corrected thermal resistance was $\mathrm{R}^{\prime}=3138\left(\mathrm{~m}^{2} \mathrm{~K} / \mathrm{W}\right)$.

The second solution proposed making the operation of the installations more efficient, together with the first envelope rehabilitation package, as follows: (1): heating installations would use efficient static heaters (with a high index of thermal loads of the metal for life) and a correlation of their size with the solutions of thermal rehabilitation of the envelope of the building; (2): the static heaters would be equipped with thermostatically regulated valves; (3): the thermo-energetic equipment in the thermal point would be automated; (4): sanitary fittings with reduced water consumption would be used for 
the preparation of domestic hot water; (5): modern equipment for domestic hot water preparation (studying the possibility of mounting equipment that uses renewable energy) would be mounted.

In order to reduce the energy consumption of the lighting system, we proposed the following solutions: (1): the complete restoration of the lighting installations and (2) the correct establishment of the number of luminaries according to the destination of the room and the level of illumination required according to the specific activity that is carried out in them, as well as the use of luminaires with fluorescent lamps or LEDs (equipped with capacitors to improve the power and electronic ballasts) because they have a high luminous efficiency (luminous flux related to electrical power).

By applying the thermal rehabilitation solutions of the building envelope, we obtained improvements of the thermal insulation performance of the building, as well as a classification in a higher class regarding the rating in the energy certificate. This the thermal rehabilitation, together with one of the indoor building services system, enabled the improved building to get the energy classification "B" and a value of $151.19 \mathrm{kWh} / \mathrm{m}^{2}$ year for the annual consumption of heat for heating, domestic hot water, and lighting. Separately on thermal utilities, the energy classifications of the reference building were:

- For heating: a "C" classification with a specific consumption of $122.97 \mathrm{kWh} / \mathrm{m}^{2}$ year.

- For domestic hot water: an "A" classification with a specific consumption of $7.26 \mathrm{kWh} / \mathrm{m}^{2}$ year.

- For lighting: an "A" classification with a specific consumption of $20.95 \mathrm{kWh} / \mathrm{m}^{2}$ year [7].

\subsection{Economic Aspects Regarding the Two Modernization Packages}

The economic analysis was a simplified form of assessing the amortization of investments. (Tables 3 and 4). This analysis was based on the following assumptions and values:

- at the date when the energy audit was performed, the average cost of the thermal energy was 55.16 Euro/Gcal, equivalent to 0.12 Euro/kWh [7], in which:

Gcal一gigacalories.

The (simple) duration of the investment recovery, $N_{R}$ (years) [7]:

$$
N_{R}=\frac{C_{I N V}}{\Delta E \times c_{e t / e e}}
$$

in which:

$C_{I N V}$ - the cost of energy modernization works (Euro).

$\Delta E$-energy savings achieved by applying energy modernization solutions ( $\mathrm{kWh} /$ year).

$c_{\text {ettee }}$ - the specific cost of heat/electricity, (Euro/kWh);

The average cost of thermal energy when the energy audit was performed, was:

$c_{e t}=0.12$ Euro $/ \mathrm{kWh}$.

Table 3. Individual consumption per consumption grid and total annual consumption in (kWh/year) for each type of proposed solution.

\begin{tabular}{ccccc}
\hline \multirow{2}{*}{ Modernization Package } & $\begin{array}{c}\text { Heating } \\
\text { Consumption }\end{array}$ & $\begin{array}{c}\text { Domestic Hot Water } \\
\text { Consumption }\end{array}$ & $\begin{array}{c}\text { Consumption of } \\
\text { Electrical Installation }\end{array}$ & $\begin{array}{c}\text { Total Consumption } \\
\text { of the Source }\end{array}$ \\
\cline { 2 - 5 } & $\mathbf{k W h} /$ Year & $\mathbf{k W h} /$ Year & $\mathbf{k W h / Y e a r}$ & $\mathbf{k W h} /$ Year \\
\hline Construction & 70,516 & 10,598 & 10,109 & 91,223 \\
\hline Constructions and plumbing & 43,221 & 2552 & 7365 & 53,138 \\
\hline
\end{tabular}

The average cost of electricity when the energy audit was performed, was: $c_{e e}=0.1$ Euro/kWh $e$ - the cost of the energy unit saved during the life of the solution (Euro/kWh) [7]:

$$
e=\frac{C_{I N V}}{\Delta T \times N_{S}}
$$

in which: 
$N_{S}$ - the estimated lifetime of the energy upgrade solution $=15$ years [7].

Table 4. Comparison of the proposed solutions.

\begin{tabular}{cccccc}
\hline \multirow{3}{*}{ Modernization Package } & $\begin{array}{c}\text { Energy-Saving } \\
\boldsymbol{\Delta E}\end{array}$ & $\begin{array}{c}\text { Lifespan } \\
\mathbf{N s}\end{array}$ & $\begin{array}{c}\text { Investment } \\
\text { Cost }\end{array}$ & $\begin{array}{c}\text { Duration of Recovery } \\
\mathbf{N R}\end{array}$ & $\begin{array}{c}\text { The Cost of Energy Saved } \\
\mathbf{E}\end{array}$ \\
\cline { 2 - 6 } & $\mathbf{k W h} /$ Year & Years & Euro & Years & Euro/kWh \\
\hline Construction & 19,933 & 30 & 40,256 & 13.46 & 0.0673 \\
\hline Constructions and plumbing & 58,018 & 20 & 43,623 & 9.40 & 0.0376 \\
\hline
\end{tabular}

\section{Discussion}

The main result of our study was that, of all the heating systems, the underfloor heating one had the lowest temperatures but the highest velocities, especially in the nave area. By comparing the two different types of turbulence models, we also observed that the $\mathrm{k}-\varepsilon$ model had temperature and air velocity values that were closer to those measured with IAQ sensors. To our knowledge, this is the first study that has evaluated two different types of turbulence models for the heating systems in churches and that has validated the $k-\varepsilon$ turbulence model for temperature and air velocity values with those measured with IAQ sensors.

The energy rehabilitation and change of the church heating system modified the energy classification of the church from the energy class D to energy class B.

We also observed that:

- The air circulation had negative effects because it generated a premature and rapid drying of all the objects—paintings, frescoes, and different wooden objects of worship—with which it came in contact.

- The volume of air that moved caused dust to rise and to be carried by air and deposited in areas with colder thermal bridges where hot air condenses and dust could be deposited.

- Another negative aspect of heating with radiators was that the discontinuous operating mode of the system caused the heating-cooling cycles of the indoor air to affect the interior finishes and heritage objects whenever religious service took place.

- The high volume of air displaced by the church made the heating of the place of worship difficult, requiring a prolonged period that imposed a continuous operating regime during the cold season.

- Heating with radiators, combined with humidity released from people, favored the phenomenon of condensation on surfaces with reduced temperatures.

In the past, the most common point of view in the design of heating systems was to achieve an economical operation with minimal maintenance effort [17-19]. The inner climate created was ignored in this equation [5].

Given that high humidity and low temperatures present in most churches diminish, the desire for the comfort of occupants in the twentieth century has led to investigations for solutions to heat the indoor climate [6].

"Climate for Culture" was a European project that took place in 2009-2014 in the field of heritage conservation [6]. This research focused on the implementation of regional climate models-new methods for simulating indoor and outdoor climate around heritage buildings. The study integrated a number of 128 heritage buildings, including many religious buildings, to assess their indoor and outdoor microclimates. Various scenarios have also been created to predict the evolution of the parameters pursued by 2100 .

The results of high-resolution climate change were achieved with the regional climate model (REMO) for the whole of Europe, including the Mediterranean basin. Within the project, building simulation tools and a simplified building model for worship buildings were developed, and these were subjected to the simulation of regional climatic environmental conditions. The resulting parameters 
allowed for the creation of maps with future risks induced by climate change on religious buildings and other heritage buildings, as well as on indoor microclimates [6].

Another study that aimed to evaluate the heating and comfort of people in heritage buildings, as well as the conservation of existing objects in them, was the European Friendly-Heating Project, carried out between 2009 and 2014 [5].

The analysis method using the CFD-Fluent software demonstrated the need for simulations in thermal comfort studies. For a more accurate and detailed analyses, are necessary in-situ investigations that place temperature and humidity sensors for a longer period of time $[13,20]$.

Numerical validation of our results was possible only for the $k-\varepsilon$ turbulence model, which had the closest temperature and air velocity values to those measured with IAQ sensors. Additionally, the differences between these values were below $10 \%$.

Our results highlight the need for the evaluation of the heating systems in order to choose the optimal one. If the situation requires even their change to new, more efficient ones with less harmful effects on cult objects (because, in general, people seek their comfort and do not keep the optimal parameters for the preservation of objects and buildings of worship), it is necessary to prioritize and reconsider the comfort needs of such buildings.

To our knowledge, this is the first study that numerically evaluated the entire indoor climate of a church. The analysis of the indoor climate was performed with several models of turbulence, both for the existing heating system and for the proposed one. We observed that the underfloor heating system ensured a high thermal comfort for the churchgoers, and, at the same time, ensured a better conservation of the architectural heritage.

\section{Conclusions}

In conclusion, our study highlighted that there is a continuous interaction between the parameters of the indoor climate and heritage conservation. Thus, we noticed that the temperature, humidity, and velocity of the air currents influenced the state of conservation of the existing heritage inside the churches, and the $k-\varepsilon$ turbulence model had temperature and air velocity values closer to those measured with IAQ sensors. In our study, the underfloor heating system was more efficient than the existing heating system (static heaters and hot air heating), ensuring heritage conservation and high thermal comfort to churchgoers.

Author Contributions: All authors had an equal contribution to this manuscript. All authors have read and agreed to the published version of the manuscript.

Funding: This research received no external funding.

Conflicts of Interest: The authors declare no conflict of interest.

\section{References}

1. Rokas, V.; Andrius, J.; Viktoras, D. Method for cost-benefit analysis of improved indoor climate conditions and reduced energy consumption in office buildings. Energies 2013, 6, 4591-4606.

2. Shui, Y.; Yumeng, C.; Yifei, S.; Fuhong, H. Simulation research on the effect of coupled heat and moisture transfer on the energy consumption and indoor environment of public buildings. Energies 2019, 12, 141.

3. Lundström, L.; Akander, J.; Zambrano, J. Development of a space heating model suitable for the automated model generation of existing multifamily buildings-A case study in Nordic Climate. Energies 2019, $12,485$. [CrossRef]

4. $\quad$ Bruelisauer, M.; Chen, K.W.; Iyengar, R.; Leibundgut, H.; Li, C.; Li, M.; Mast, M.; Meggers, F.; Miller, C.; Rossi, D. Bubble ZERO-design, construction and operation of a transportable research laboratory for low exergy building system evaluation in the tropics. Energies 2013, 6, 4551-4571. [CrossRef]

5. Camuffo, D. The friendly heating project and the conservation of the cultural heritage preserved in churches. In Developments in Climate Control of Historic Buildings; Fraunhofer IRB Verlag: Stuttgart, Germany, 2010; pp. 7-12. 
6. Camuffo, D.; Pagan, E.; Schellen, H.; Limpens-Neilen, D. A practical guide to the pros and cons of the various heating systems with a view to the conservation of the Cultural Heritage in Churches. In Results of the European Project Friendly Heating EVK4-CT-2001-00067; Fraunhofer IRB Verlag: Linderhof, Germay, 2014.

7. MLPTL. NP 048-Normativ Pentru Expertizarea Termică și Energetică a Clădirilor Existente și al Instalațiilor de Incălzire și Preparare a Apei de Consum Aferente Acestora; MLPTL: Hamburg, Germany, 2000.

8. Beck, W.; Koller, M. Problems of heating within historic buildings of Austria. Stud. Conserv. 2013, 25, $22-29$. [CrossRef]

9. Zhang, Z.; Zhai, Z.J.; Chen, Q.Y. Evaluation of various turbulence models in predicting airflow and turbulence in enclosed environments by CFD. HvacR Res. 2007, 13, 871-886. [CrossRef]

10. Cortés, M. CFD modeling of basic convection cases in enclosed environments: Needs of CFD beginners to acquire skills and confidence on CFD modeling. RIC 2014, 29, 22-45.

11. Wang, H.; Zhiqiang, J.Z. Advances in building simulation and computational techniques: A review between 1987 and 2014. Energ. Build. 2016, 128, 319-335. [CrossRef]

12. Tian, W.; Sevilla, T.A.; Zuo, W. A systematic evaluation of accelerating indoor airflow simulations using cross-platform parallel computing. J. Build. Perform. Simul. 2017, 10, 243-255. [CrossRef]

13. Tian, W.; Xu, H.; Wangda, Z.; Sohn, M.D. Building energy simulation coupled with cfd for indoor environment: A critical review and recent applications. Energ. Build. 2018, 165, 184-199. [CrossRef]

14. Lim, J.; Yoon, M.S.; Al-Qahtani, T.; Nam, Y. Feasibility study on variable-velocity air conditioner under hot climate based on real-scale experiment and energy simulation. Energies 2019, 12, 1489. [CrossRef]

15. Frontczak, M.; Wargocki, P. Literature survey on how different factors influence human comfort in indoor environments. Build. Environ. 2011, 46, 922-937. [CrossRef]

16. Bassam, M.; Cantin, R.; Guarracino, G. Comparison of thermal comfort algorithms in naturally ventilated office buildings. Energy Build. 2008, 40, 2215-2223.

17. Andrea, V.; Luca, M.; Chiara, C. How the urban environment affects the microclimate and the building energy demand for the city of Rome. Therm. Sci. 2019, 23, S1035-S1042.

18. Yunyang, Y.; Kathryn, H.; Jian, Z.; Wangda, Z.; Gang, W. A methodology to create prototypical building energy models for existing buildings: A case study on U.S. religious worship buildings. Energy Build. 2019, 194, 351-365.

19. Schellen, H.; Lambertus, H. Heating Monumental Churches-Indoor Climate and Preservation of Cultural Heritage; Technische Universiteit Eindhoven: Eindhoven, The Netherlands, 2002.

20. Marco, P.; Kristian, F. Indirect investigation: Building simulation. In Historic Indoor Microclimate of the Heritage Buildings; Springer: Berlin, Germany, 2018; pp. 100-102. 